\title{
EFEECT OF SILICA ADDITION ON MECHANICAL STRENGTH OF HYDRAULIC HARDENED CALCIUM PHOSPHATES
}

\author{
YOUZO KAWAHARA, KIMIHIRO YAMASHITA and TAKAO UMEGAKI \\ Department of Industrial Chemistry, Faculty of Engineering, \\ Tokyo Metropolitan University \\ Minamiosawa, 1-1, Hachioji, Tokyo 192-03
}

\begin{abstract}
Porous silica was added to calcium phosphate cements on hydrolysis in order to increase bulk density and improve bending strength of hydraulic apatite.
\end{abstract}

\section{INTRODUCTION}

Bending strength of most hydraulic hardened bodies are lowered by the presence of pores in the bodies. Generally on hydraulic processes, it is important to reduce the amount of water in cement slurry. In case of ordinary Portland cement water-reducing agents such as sodium lignin sulfonate are used while fine silica fume is sometimes added to maintain workability of the cement slurry. Moreover, silanol groups is known to promote formation of apatites although the effect of the silanol is not clarified.

In the present paper synthesized porous silica was added to calcium phosphate slurry in order to examine the effects of silica addition described above. Hydraulic bodies were prepared from the products obtained by thermal decomposition of apatite and x-ray and IR analyses and measurement of bending strength for hydrated calcium phosphates were carried out.

\section{EXPERIMENTAL PROCEDURE}

Starting mixtures of calcium phosphates were prepared by thermal decomposition of apatite, which was heated at $1450^{\circ} \mathrm{C}$ for 5 hours and cooled in $\mathrm{N}_{2}$ stream ${ }^{1)}$. Silicaadded calcium phosphate slurries were hydrated at $80^{\circ} \mathrm{C}$ for 5 hours. Hardened bodies 
so obtained were analyzed by x-ray diffraction and IR spectrum and bending strength was measured by the three-point method. Porous silica powders were prepared by decomposition of organic and inorganic composites of silicates ${ }^{2)}$.

\section{RESULTS AND DISCUSSION}

X-ray diffraction and IR spectra of hydrated calcium phosphates containing silica powder indicated calcium-deficient apatites as far as those obtained in the present study were concerned.

The values of surface area for synthesized silica are shown in Table 1.

Table 1 Porous silica

\begin{tabular}{lccc}
\hline & SG-230 & SG-370 & SG-570 \\
\hline $\begin{array}{l}\text { Surface area }\left(\mathrm{m}^{2} / \mathrm{g}\right) \\
\begin{array}{l}\text { Micropore } \\
\text { surface area }\left(\mathrm{m}^{2} / \mathrm{g}\right)\end{array}\end{array}$ & 226.9 & 369.5 & 573.1 \\
$\begin{array}{l}\text { Micropore } \\
\text { volume }\left(\mathrm{m}^{2} / \mathrm{g}\right)\end{array}$ & 0.064 & 58.7 & 335.0 \\
\hline
\end{tabular}

Figure 1 shows the change in cement/water ratio with amount of the porous silica added.

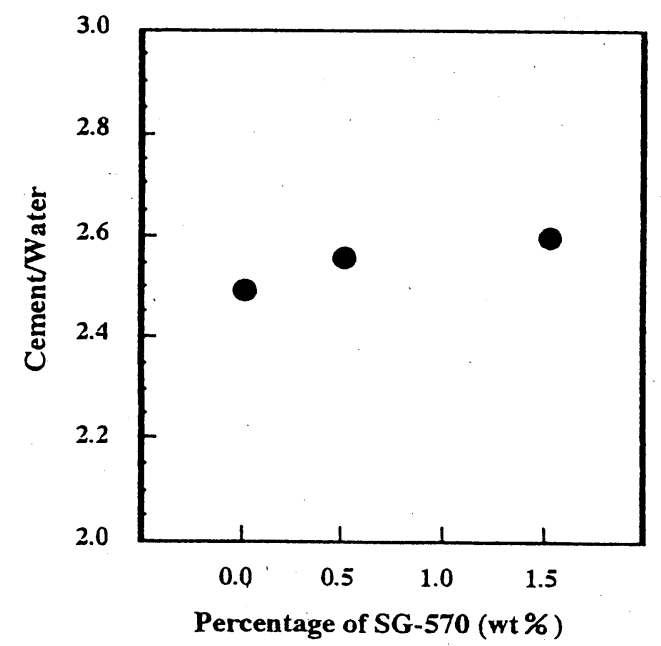

Fig. 1 Relation between cement/water ratio and amount of silica.

Silica added: SG-570 in Table 1. 
It was found that the amount of water on preparation of calcium phosphate slurry was able to be slightly reduced by addition of silica.

Figure 2 show that bending strength of calcium phosphate hardened body increased according to reduction of water amount. Silica addition of $0.5 \mathrm{wt} \%$ was effective while the strength was not improved in case of over $1 \mathrm{wt} \%$ of silica. Similar effects were found on addition of commercial silica gel to the same calcium phosphate slurries.

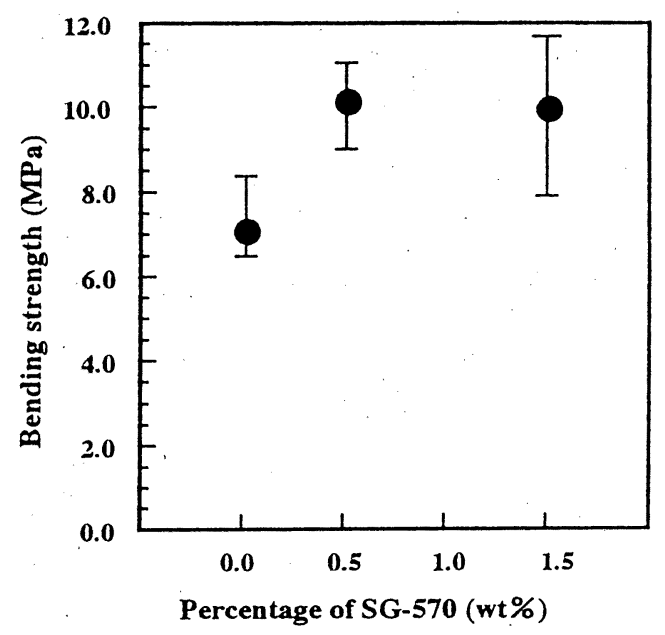

Fig. 2 Change in bending strength with amount of silica addition.

However, effect of silanol group on silica surface was not found as Fig. 3 shows since bending strength of silica-added hardened bodies did not depend on surface area. Another possible explanation about the relation indicated in Fig. 3 may be the absence of silanol group on silica surface.

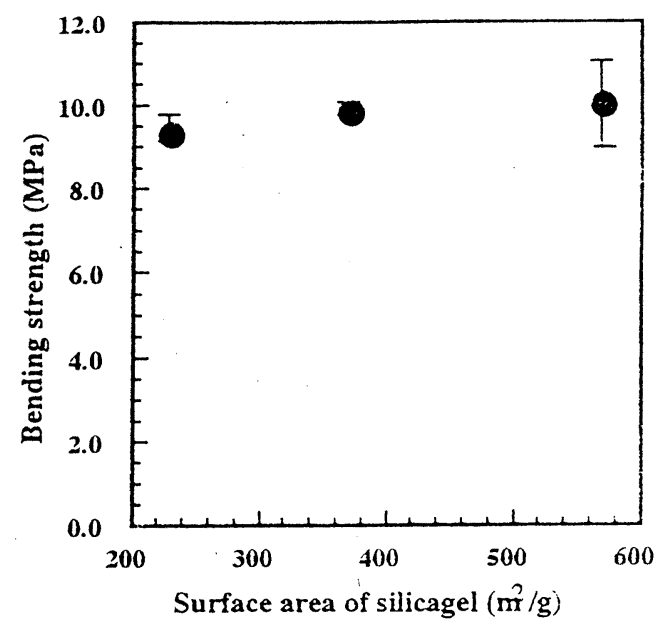

Fig. 3 Relation between bending strength and surface area. 


\section{CONCLUSIONS}

Small amount of silica-addition(0.0-1.0 wt\%) reduced the amount of water in calcium phosphate slurries and increased the bending strength of calcium phosphate hardened bodies. Since the strength of the hardened bodies did not depend on surface properties of silica, workability of calcium phosphate cements might be improved by silica.

Silica-added hydraulic calcium phosphate bodies will be strengthen by appropriate mixing procedure of slurry and surface modification of silica by silanol groups.

\section{ACKNOWLEDGMENT}

The authors wish to express their thanks for financial support by Grant-in Aid for Co-operative Research (No.037305063) and Grant-in Aid for Developmental Scientific Research(No.07555275) from the Ministry of Education, Science, Sports and Culture, Japan.

\section{REFERENCES}

1)K.MUROYAMA, T.MATSUMOTO, K.YAMSHITA, AND T.UMEGAKI, Inorganic Materials. $\underline{3}, 380(1996)$.

2) Y.CHUJO, Ceramic Japan, 29, 971(1994). 